University of Louisville

ThinkIR: The University of Louisville's Institutional Repository

Electronic Theses and Dissertations

$12-2011$

\title{
Pharmacists as mid-level healthcare providers and the clinical results of a pharmacist-led diabetes disease management program.
}

Benjamin Maurice Risner 1983-

University of Louisville

Follow this and additional works at: https://ir.library.louisville.edu/etd

\section{Recommended Citation}

Risner, Benjamin Maurice 1983-, "Pharmacists as mid-level healthcare providers and the clinical results of a pharmacist-led diabetes disease management program." (2011). Electronic Theses and Dissertations. Paper 1210.

https://doi.org/10.18297/etd/1210

This Master's Thesis is brought to you for free and open access by ThinkIR: The University of Louisville's Institutional Repository. It has been accepted for inclusion in Electronic Theses and Dissertations by an authorized administrator of ThinkIR: The University of Louisville's Institutional Repository. This title appears here courtesy of the author, who has retained all other copyrights. For more information, please contact thinkir@louisville.edu. 


\title{
PHARMACISTS AS MID-LEVEL HEALTHCARE PROVIDERS AND THE CLINICAL RESULTS OF A PHARMACIST-LED DIABETES DISEASE MANAGEMENT PROGRAM
}

\author{
By \\ Benjamin Maurice Risner \\ B.S., M.D.
}

\author{
A Thesis \\ Submitted to the faculty of the \\ School of Medicine of the University of Louisville \\ In Partial Fulfillment of the Requirements \\ for the Degree of \\ MASTER OF SCIENCE \\ Pharmacology and Toxicology \\ University of Louisville \\ Louisville, Kentucky
}

December 2011 
Copyright 2011 @ by Benjamin Maurice Risner

All Rights Reserved 


\section{PHARMACISTS AS MID-LEVEL HEALTHCARE PROVIDERS AND THE CLINICAL RESULTS OF A PHARMACIST-LED DIABETES DISEASE MANAGEMENT PROGRAM}

By

Benjamin Maurice Risner

B.S., M.D.

A Thesis approved on

November 28, 2011

By the following Thesis Committee:
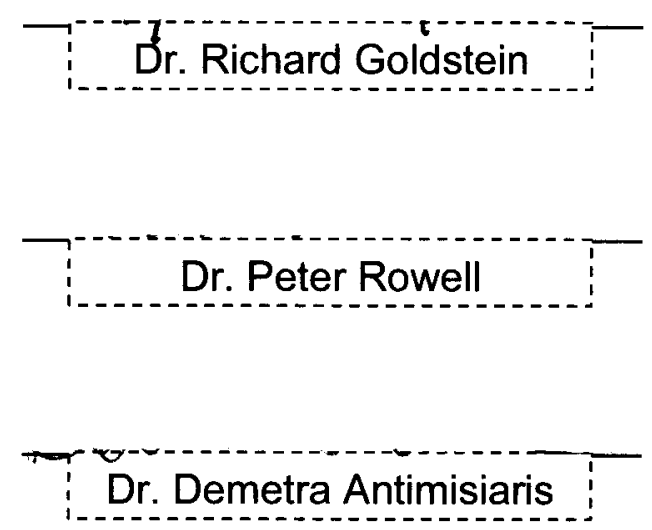


\section{ACKNOWLEDGEMENTS}

I would like to thank Dr. Richard Goldstein M.D., Ph.D., Dr. Demetra Antimisiaris PharmD., and Dr. Peter Rowell Ph.D. for their unwavering support throughout this process. I would also like to thank Donna Matthews, Janet Robbins, Tina Claypool, PharmD., and Alice Cissel for their help in gathering and analyzing the data needed for this study. 


\begin{abstract}
PHARMACISTS AS MID-LEVEL HEALTHCARE PROVIDERS AND THE CLINICAL RESULTS OF A PHARMACIST-LED DIABETES DISEASE MANAGEMENT PROGRAM

Benjamin Maurice Risner
\end{abstract}

$11 / 28 / 2011$

Advancements in medical therapy have augmented resources available to physicians to treat disease and, because of this, spending on prescription drugs has doubled in the past decade. Increasingly, clinical trials are demonstrating the benefits of aggressive disease management in reducing morbidity and mortality. Physicians treating patients with chronic conditions must balance the benefits of combination drug therapy against the risk of adverse drug events and drug interactions. For instance, evidence-based practice guidelines in patients with diabetes and multiple comorbidities require combination therapy in order to reduce morbidity and mortality. Patients with polymorbidity require the attention of multiple physicians, further fragmenting patient care and increasing polypharmacy related issues. Pharmacists are increasingly recognized for expertise in pharmacodynamics and pharmacokinetics and have been shown to be beneficial when utilized in patient care. Pharmacists are in a key position to help physicians manage the balance between optimal disease management and the risks of polypharmacy. 


\section{TABLE OF CONTENTS}

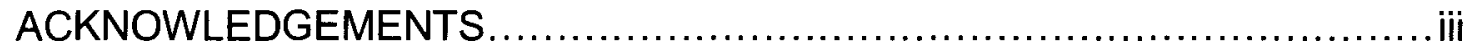

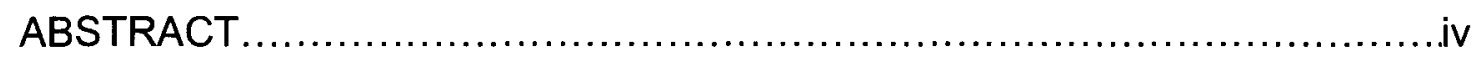

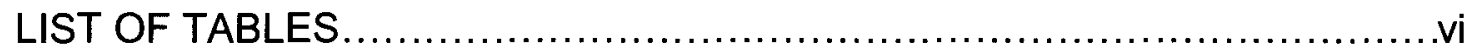

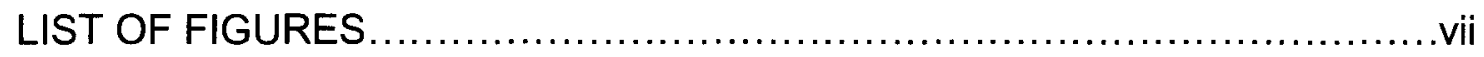

$\begin{array}{ll}\text { Chapter } & \text { Page }\end{array}$

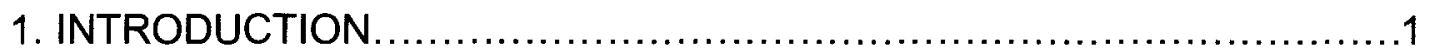

2. PHARMACISTS AS MID-LEVEL PROVIDERS $\ldots \ldots \ldots \ldots \ldots \ldots \ldots \ldots \ldots \ldots \ldots$

3. CLINICAL RESULTS OF A PHARMACIST-LED DIABETES DISEASE

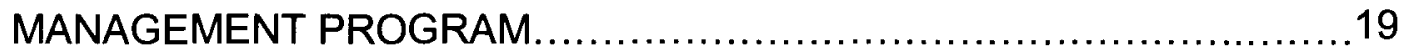

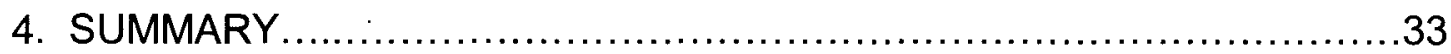

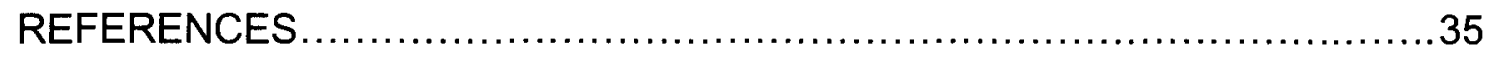

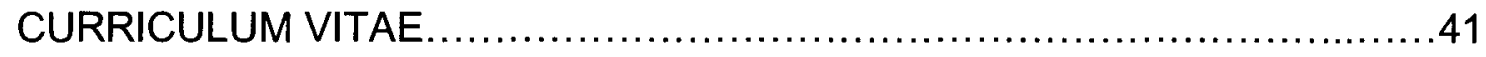




\section{LIST OF TABLES}

Table

1. Areas of competency in diabetes education identified by the American Association of Diabetes Educator. 


\section{LIST OF FIGURES}

Figure

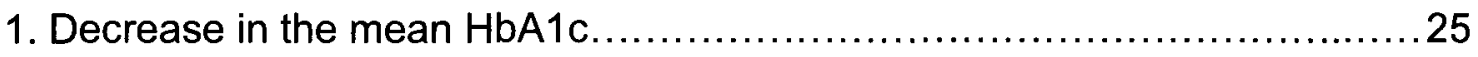

2. Decrease in the mean systolic blood pressure (SBP) at the 0 and 12 month interval.

3. Decrease in the mean diastolic blood pressure (DBP) at the 0 and 12

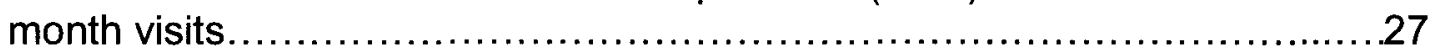

4. Decrease in the mean basal metabolic index (BMI) at the 0 and 12 month

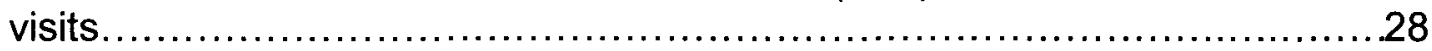

5. Decrease in the mean care gap index (CGI) at the 0 month (pre-enrollment) and 12 month (post-enrollment) visits. 29 


\section{CHAPTER 1}

\section{INTRODUCTION}

\section{Risks and Burdens of Polypharmacy}

Abiding by evidence-based standards of care for patients with a chronic disease often requires that healthcare providers utilize multiple medication therapy to maximize patient outcomes. However, pursuance of improved patient outcomes using multiple medication therapy predisposes patients to polypharmacy. Polypharmacy is generally defined as the ineffective and inappropriate use of multiple prescription and over the counter (OTC) medications to the point at which it is detrimental to patient health.[1, 2] The negative consequences of polypharmacy burden patients, healthcare providers, and third-party payers alike.

Some common risk factors for polypharmacy include increased age, multiple prescribers, multiple medication therapy, institutionalization, and polymorbidity.[1-3] For patients diagnosed with a chronic disease with complicating and concurrent comorbidities, multiple medication therapy is necessary for adequate treatment and polypharmacy may be unavoidable.[4] For example, patients diagnosed with diabetes and common comorbidities such as hypertension and hyperlipidemia may easily require five or more medications a day to meet the clinical targets for each of these three conditions.[5] Paradoxically, the complex multidrug regimes necessary to treat patients with 
polymorbidity may predispose them to complications associated with polypharmacy.[6-8]

Side effects of polypharmacy include decreased medication compliance, adverse drug reactions (ADR), increased costs of care, and increased use of healthcare services (hospitalizations, emergency room visits, etc.). The risk of polypharmacy associated complications is especially great among patients that have concurrent comorbidities such as depression, congestive heart failure, and are being treated by multiple healthcare providers.[1] Further, the inverse relationship between polypharmacy and medication compliance is routinely found in patients with diabetes and contributes to poor blood glucose control.[6, 7]

The negative consequences of polypharmacy are disproportionally felt by the elderly as $37 \%$ of individuals over the age of 60 report regular usage of five or more medications.[9] The elderly are more susceptible to ADRs given their decreased health literacy and age-related changes in physiology that alter the concentration and clearance of medications.[8] ADRs cannot only be lifethreatening, they are also a significant cause of hospitalizations and increased costs.[10-12] In addition, declining cognitive function and decreased mobility can make adherence to medication regimens more difficult.[7]

\section{Effects of Mismanagement on Costs and Utilization}

Prescription drug expenditures are expected to escalate in coming years from $\$ 234.1$ billion in 2008 to $\$ 458$ billion in 2019.[13] Research and development by the pharmaceutical industry have increased the amount of improved, more effective medical therapy available to treat diseases. In addition, 
marketing campaigns directed toward patients and physicians have increased the demand for these newer, more costly medications. As such, during 1999 2009 the number of dispensed prescriptions increased $39 \%$ along with the proportion of patients who reported use of multiple prescription medications.[14] With the increased cost and utilization of prescription medications, both patients and third-party payers alike stand to benefit from optimized medication therapy. Medication mismanagement is a substantial contributor to overall healthcare spending. ADRs, for instance, are a significant cause of hospitalizations and emergency room visits. Elderly patients are the most likely patient population to experience severe ADRs with the most common causes of hospitalization being falls, orthostatic hypotension, and delirium.[8, 15, 16] Although ADRs can be present at any age, their toll on the elderly population is greater because of their decreased physiological reserve. Elderly patients have decreased muscle mass, increased body fat, decreased renal function, and decreased hepatic mass altering their ability to metabolize medications. Because of this, the clinical manifestations related to ADRs are more pronounced among elderly patients. Additionally, it has been determined that most hospitalizations involving ADRs are preventable.[16] In fact, hospitalizations often result from errors such as incorrect dosage, noncompliance, or omission of drug therapy.[15] The effects of ADRs can also be misdiagnosed by healthcare providers who then provide patients with additional treatment, further worsening the patient's polypharmacy. Urinary incontinence, weight loss, cognitive impairment, malnutrition, constipation, and insomnia are all associated with polypharmacy 
and are common complaints among elderly patients but are not often recognized as ADRs. Due to this, patients are routinely offered medications to mitigate their symptoms, further worsening their polypharmacy.

\section{Pharmacist-led Interventions: The Case for Diabetes}

The ineffective use of medication therapy has a serious effect on the most vulnerable aspects of our population that ripples throughout the entire healthcare system. Moreover, the preventable nature of most ADRs makes further tolerance of their subsequent burden to both patients and third-party payers unacceptable. Effectively combating medication therapy mismanagement will require additional oversight from pharmacists who are experts in pharmacodynamics and pharmacokinetics.

With the rising tide of obese and overweight Americans, the prevalence of diabetes and obesity related comorbidities such as hypertension and heart disease are expected to increase more than other chronic conditions over the next decade. Additionally, though diabetes is currently most prevalent in individuals $>65$ years old, the great majority of newly diagnosed cases were among individuals who were $45-64$ years of age.[17]

With the average age of diagnosis decreasing, the high number of comorbidities, and the cost of treatment increasing, diabetes is poised to become an even greater driver of increased health spending. The decreased amount of time that physicians are allotted to see patients combined with the more complex medication regimens needed to achieve clinical targets in patients with diabetes will further worsen the rates of ADRs and increase costs associated with 
ineffective medication management.[18, 19] Primary care physicians are also limited in the amount of problems that they are able to address in the decreased amount of time they have per patient visit. Primary care physicians' time is divided between providing direct patient care, reviewing imaging and lab reports, and addressing phone calls. Though major areas of concern to the patient may be adequately resolved, it is likely that potential issues with polypharmacy and ineffective drug therapy will be overlooked.[19]

With the increased burden to patients and third-party payers and the inability of healthcare providers to ensure that a patient's medication management is optimized, pharmacists are uniquely poised as experts in the field of medication therapy management. Pharmacists' provision of medication therapy management (MTM) services can increase medication adherence, improve patient literacy, eliminate duplications in therapy, maximize medication therapy, and decrease the risk of ADRs. Through optimization of medication therapy, pharmacists can improve patient clinical outcomes and reduce costs associated with inadequate patient management.[20] 


\section{CHAPTER 2}

\section{PHARMACISTS AS MID-LEVEL PROVIDERS}

Though traditionally pharmacists have been employed in various settings throughout the healthcare industry, their role as service providers has generally been confined to dispensing and distributing medications. As drug costs and the number of patients consuming multiple prescription medications increases, the opportunities for pharmacists to act as mid-level providers (MLP) and provide medication therapy management (MTM) services is growing. MTM services provided by pharmacists currently include comprehensive medication reviews, medication counseling, patient education, collaborative drug therapy management (CDTM), and disease management programs.

Pharmacist provision of MTM services have been shown to improve patient outcomes, especially among patients on multiple medications and with more than one prescriber, such as ICU patients and those with chronic conditions.[21-23] Patients with these conditions are predisposed to increased morbidity and mortality associated with polypharmacy. Polypharmacy is generally defined as the ineffective and inappropriate use of multiple prescription and over the counter (OTC) medications to the point at which it is detrimental to patient health.[1, 2] Polypharmacy has been shown to increase the number of adverse drug events (ADE) and decrease medication compliance, among other things. 
As one may imagine, the direct and indirect healthcare costs associated with polypharmacy and suboptimal disease management are staggering. In fact, the healthcare costs for a patient diagnosed with a chronic disease are five times greater than that of patients who aren't.[23] Many third-party payers including Medicaid/Medicare, self-insured employers, and private insurance companies, have begun utilizing pharmacist provided MTM services to reduce their overall healthcare costs and improve patient health.[24-28]

As healthcare demands continue to increase, the need for pharmacists who can act as mid-level providers and provide MTM services will grow. Despite data that demonstrate the benefits of expanding the pharmacist's role in healthcare to include MTM services, some physicians are understandably anxious about the increasing profile of non-physician providers in healthcare.[29] However, as demands for the cost-effective provision of healthcare services continue to rise, pharmacists will become an invaluable resource for physicians and payers in optimizing medication management to achieve desired patient outcomes.[30] The purpose of this manuscript is to advocate for the expanded role of pharmacists in the clinical setting and explain that their inclusion in providing care benefits patients and physicians alike.

\section{Background}

In the 1950s, pharmacists began to expand their scope of practice beyond the dispensing and distribution of medication, as pharmacists employed with the Indian Health Service (IHS) pioneered the concept of clinical pharmacy and pharmaceutical care. When IHS clinics were first established, many were located 
in remote areas of the country with limited resources, and an overwhelming need for medical care necessitated that pharmacists play a larger role in the care of patients.[31] As federal employees, IHS pharmacists were not limited by individual state laws regulating their scope of practice.[32] As such, IHS pharmacists were often utilized to provide comprehensive medication reviews, screen patients for conditions such as diabetes and hypertension, and to help coordinate care. The expanded, collaborative relationships that the IHS pharmacists had with physicians and other healthcare providers also extended to the inpatient setting as pharmacists would round with physicians to provide guidance on questions that arose regarding medication.

Given the cultural differences and limited education that were common among the patient population, collaboration among providers was essential to ensure that patients understood their medical condition and remained compliant with their medications. To help facilitate this, the IHS pharmacists had access to their patient's full medical records, which allowed the pharmacists to make sure that patients were receiving optimal drug therapy. Also, because patients often visit their pharmacist more often than their physician, pharmacists were able to encourage and facilitate follow-up with the primary care providers.[33, 34]

Aside from the IHS, the Veteran's Health Administration (VHA) has also utilized pharmacists in expanded clinical roles, working as mid-level providers. Building on the experiences and success with the IHS, the VHA further expanded the clinical roles of pharmacists and furthered their incorporation into the primary care system. The VHA established several specialty clinics where pharmacists, 
with additional training in the treatment of specific conditions, treated patients under a collaborative drug therapy management (CDTM) agreement with the patient's prescriber. The CDTM established protocols under which the pharmacist could initiate, alter, or discontinue therapy to achieve optimal disease management. The clinics specialized in areas such as diabetes, hypertension, nephrology, anticoagulation, and HIV. As an example, if a patient at the anticoagulation clinic was determined to have a sub-therapeutic INR, the pharmacists had the autonomy to alter the patient's medication to achieve a therapeutic INR.[35, 36]

In 1996, the city of Asheville, North Carolina, a self-insured employer, found that chronic diseases such as diabetes were the leading drivers behind its increasing healthcare costs. Previously, pharmacist-led clinics were provided by integrated health systems such as the VHA and IHS. The Asheville Project, however, established pharmacist-led diabetes clinics in community pharmacies and used incentives such as waived co-pays for diabetes medications and free testing supplies to ensure patients remained engaged in the program.

The Asheville Project sought participation and advice from local physicians, dieticians, and area pharmacists in development and implementation of the pharmacist-led intervention. The pharmacists in the Asheville Project met with the patients regularly to address blood glucose levels, lipids, and weight management. The pharmacist would work with the patient to resolve any medication issues or treatment questions that they had. The pharmacist would 
keep documentation of the visit and send the patient's physician a note detailing the visit and any areas of concern that they felt needed to be addressed.[25] Aside from popularity among patients and physicians, the pharmacist-led intervention in the Asheville Project resulted in consistent improvements in the patient's HbA1c and serum lipid values over 14 months of enrollment.[25] As a result of the intervention, the patient population also had lower healthcare costs as their clinical improvement led to decreased utilization of costly healthcare services such as hospitalizations and emergency room visits.

The success of the Asheville Project has since been translated into pharmacist-led disease management programs being established by other thirdparty payers across the country. For instance, Medicare Part $D$ began providing MTM services to patients with a high utilization of services as a way to reduce medication related costs.[37] In addition to Medicare, many state Medicaid programs have also started to utilize pharmacists' MTM services.[38] For instance, in 2005 the state of Minnesota passed legislation that would allow pharmacists to be reimbursed through the state's Medicaid budget for MTM services provided to patients with chronic illnesses and on multiple medications. Within the first year of MTM implementation, pharmacists were able to identify and correct numerous medication errors and the number of diabetic patients enrolled in the program who had optimal control was greater than the state average.[28] Similar Medicaid provided MTM programs have been developed in states like lowa, Missouri, and North Carolina.[27, 39] 


\section{Unique Among Mid-Level Providers}

Mid-level providers are generally classified as non-physician practitioners (NPP) that provide direct patient care in both the hospital and outpatient setting, often acting in the role of a "physician extender." Mid-level providers fulfill a variety of roles in healthcare and include nurse practitioners (NP), certified nurse midwives (CNM), physician's assistants (PA), and clinical nurse specialists (CNS). While the training and certification requirements of each mid-level provider varies, in general, mid-level NPP's have two years of master's level training, focusing on the provision of basic clinical services such as diagnosing, examining, and treating patients.[40]

Limitations on the mid-level, NPPs scope of practice vary by state. However, in most states they are granted prescriptive authority and allowed a broad range to practice within their ability. The variety of services offered by NPPs in both the hospital and outpatient setting include physical exams, ordering and interpretation of diagnostic exams, and minor, noninvasive procedures. However, mid-level NPPs are reimbursed at a lower rate by Medicare than physicians because they are confined, by virtue of their training, to providing care for less complex patients.[40, 41]

Pharmacists differ from other mid-level NPPs in a number of ways including education, training, and scope of practice. The American Association of Colleges of Pharmacy (AACP) mandated in 1990 that Doctorate of Pharmacy (PharmD) would be the first professional degree offered by Schools of Pharmacy.[42] Pharmacists would still undergo rigorous training regarding the 
appropriate usage, pharmacology, and interactions of drugs as one might expect. However, pharmacy students are now offered a great deal of clinical training in patient care and communication as a part of their PharmD program. Also, pharmacists, unlike other mid-level NPPs, have the option of completing a residency, becoming certified, and focusing their careers in subspecialty areas such as nutrition, oncology, HIV, critical care, and others.[42]

Given the extent of their training, pharmacists now have a vast array of knowledge not only on the mechanisms of various drugs but also on how they interact with each other and the human body to cure a patient. Because their training is so extensive, pharmacists possess a unique skill set that is not shared with other mid-level NPPs or even physicians.[41] Given the potential benefit that pharmacists can provide to both patients and physicians, their level of involvement in patient care will only continue to grow.

Pharmacists' role as healthcare providers has largely been defined by the dispensation and distribution of medications. Increasingly, however, automated filling systems and pharmacy technicians are dispensing medications under pharmacist supervision. While this transition has made pharmacies more efficient and helped control costs, it has left pharmacists seeking a way to expand their ability to provide services to patients. In addition, now that all pharmacists entering into practice have obtained their PharmD, many feel that their training and abilities are being underutilized.

As stated earlier, MTM contains a broad range of cognitive services that pharmacists provide beyond dispensing and distributing medication. Some of the 
services that pharmacists offer under MTM include chronic disease management, immunizations, medication surveillance, comprehensive medication reviews, and pharmacotherapy. These MTM services are being performed by pharmacists in a variety of both settings including hospitals and outpatient clinics.[43, 44] Provision of MTM services has shown increased medication compliance, optimization of therapeutic regimens, and a decrease in adverse drug events.[44] Patient satisfaction with the care they receive from pharmacists providing MTM services such as chronic disease management is generally positive.

\section{Benefit of MTM Services}

Polypharmacy is a condition that is prevalent in individuals with chronic diseases and the elderly. The elderly population consumes almost $30 \%$ of the prescription medications dispensed in the United States and, on average, take 4.5 prescription medications and two over the counter (OTC) medications.[45] Individuals with multiple chronic conditions such as diabetes, congestive heart failure, and COPD, are also likely to be on multiple prescription and OTC medications. Polypharmacy increases the likelihood that a patient will experience an ADE or other medication related event requiring a hospitalization and reduces patients' adherence to medication regimens resulting in suboptimal disease management.

Given the substantial cost increase that is associated with polypharmacy, MTM services can be particularly beneficial. Pharmacists are able to perform comprehensive medication reviews and minimize the possibility of ADEs while 
simultaneously optimizing the patient's medication management.[46] In addition, a pharmacist review of a patient medication list can lead to discontinuation of ineffective or duplicated medication therapy. Given the high cost of prescription medications and the outcomes that can be associated with ADEs, MTM services are an essential component to the proper management of patients.

\section{MTM Implementation}

In 2003, the Medicare Prescription Improvement and Modernization Act (MMA) became signed into law, providing increased prescription drug coverage for individuals enrolled in Medicare. Beginning in 2006, the Center for Medicare Services (CMS) began requiring providers of Medicare Part D (PDP) to provide MTM services as a way to save costs, reduce drug interactions and ADEs, and optimize medication management.[40] The MTM services focused on identifying and resolving medication related issues and providing comprehensive medication reviews for patients on multiple Part D medications with multiple chronic conditions whose drug costs were greater than $\$ 4,000$. After realizing a significant savings in drug costs and reductions in medication related errors, CMS has recently recommended an expansion of their MTM services and has reduced the cost threshold for eligible patients to $\$ 3,000$.[40]

Though MTM services have been shown to produce better patient outcomes and reduce costs, many third-party payers are still not covering these services. In addition, pharmacists cite an inadequate representation of MTM services in the current medical coding system as a significant barrier to obtaining payment for their services. $[47,48]$ Also, many third-party payers are not fully 
recognizing MTM services as separate from dispensing services and, because of this, pharmacists are unable to bill for their services. Pharmacists are also not recognized by third-party payers as healthcare providers in the same way that NP, PA, and CPSs are.[48] Because of this, pharmacists are often not able to bill directly for their services and instead must bill MTM services as incidental to physician services.[40]

Up until recently, MTM services provided by pharmacists were rare outside of large, academic settings. Pharmacists working in community-based retail pharmacies still spend a great deal of their time dispensing medications to patients. In order to fully implement MTM services, pharmacies would have to invest more resources into hiring pharmacists and pharmacy technicians. Pharmacists would also have to find a way to document and bill for their services and establish a greater amount of communication among physicians in their area.[49] Currently, with many different health information technology (HIT) systems being utilized across the country there is no standardized billing and documentation system which further hinders pharmacists' ability to provide MTM services.

In order for patients, providers, and payers to receive the greatest amount of benefit from MTM services, there must be cooperation and collaboration among all of a patient's healthcare providers. Most successful MTM implementation has occurred in environments that are conducive to collaboration among the different healthcare providers and integration of healthcare services. 
Most payers find it necessary to include incentives for patients to remain engaged with their pharmacist.[28] While it is true that most individuals visit their pharmacist more than their physician, some pharmacists have complained of trouble getting patients to follow up after an initial visit. However, financial incentives such as waived copayments for medications can entice patients to remain engaged.[50]

\section{MTM Future}

Included in the Affordable Care Act (ACA) was a provision for the development of Accountable Care Organizations (ACO) as a new comprehensive, patient-centered method delivering patient care that rewards healthcare providers for the quality of the care they provide. ACOs are accountable to patients and payers for the cost, quality, and efficiency of the care that they provide.[51] Since the current fee for service method of paying healthcare increases utilization without increasing quality, it is likely that a capitation system of payment will be adopted with provisions for shared savings.[52] The capitation method of payment provides a lump sum for healthcare services whether patients utilize services or not. Patients with chronic

diseases who have been enrolled in MTM services have shown a decrease in the number of ER visits and hospitalizations. Taking the highest risk individuals enrolled in a health plan and enrolling them in a pharmacist-led MTM service chronic disease management is a proven method of reducing costs and improving patient outcomes.[52] 
Pharmacists can also figure prominently in Patient Centered Medical Homes $(\mathrm{PCMH}) . \mathrm{PCMH}$ is a practice model that places the primary care physician as the leader of a patient's healthcare team.[53] Aside from the PCMH serving as a patient's gateway into the healthcare system, it will also provide patients with disease management and other services that are not currently offered in most community primary care offices. Having access to a patient's full medical record, pharmacists will be able to collaborate directly with physicians in the PCMH to maximize patient outcomes.[46] In addition, given the likelihood that capitation and shared savings will become the preferred form of payment for patient care in the future, pharmacist provision of MTM services will be essential to control costs and improve patient outcomes.[54]

From the data presented, it can be clearly seen that pharmacists as midlevel providers of MTM services have the potential to benefit patients, payers, and providers. Chronic disease management programs that are administered by pharmacists have been shown to significantly reduce costs to third-party payers. Aside from the savings realized immediately by payers, it is hoped that better management of patients diagnosed with diabetes, for instance, will produce longterm cost savings by reducing complications that result from poorly managed blood glucose levels such as renal failure.

Further recognition of pharmacists as mid-level providers will require a greater amount of understanding by physicians and payers as to the benefits of providing MTM services.[37] In addition, physicians and other providers are currently paid under a fee-for-service arrangement whereby they are paid more 
for additional services than they provide. Until healthcare providers are provided an incentive to maximize preventative services and emphasis wellness among their patients, MTM services will remain underutilized by the healthcare community. 


\section{CHAPTER 3}

\section{CLINICAL RESULTS OF A PHARMACIST-LED DIABETES DISEASE MANAGEMENT PROGRAM}

The impact of chronic diseases on healthcare costs has become an increasingly important topic. Indeed, the impact of only five or six chronic disease including diabetes, hypertension, cardiovascular disease (CVD), asthma, chronic obstructive pulmonary disease (COPD), and musculoskeletal disease account for $75 \%$ of the annual health costs in the U.S.[55] Medical advances over the last half of the twentieth century have provided an abundance of new opportunities to better treat and manage disease. These advances have not only improved the quality of life for many people but have also increased the life expectancy for individuals suffering from chronic diseases. However, the rising life expectancy coupled with the advanced medical technology required for long-term care of patients diagnosed with a chronic disease has led to an exponential growth in the cost of healthcare.[55, 56] The increased cost of healthcare provides a significant barrier to those seeking medical treatment while also hampering economic growth and contributing to inflation nationwide.[56] Moreover, a recent survey of CEOs revealed that employee healthcare places the greatest cost pressure on American businesses.[57]

Diabetes, primarily type II diabetes, stands out as a particularly significant driver for healthcare spending.[17] Diabetes is also one of the chronic diseases 
where the annual rate of increase shows little sign of abating.[58] The increasing incidence of diabetes has been closely associated with the emergence of the obesity epidemic in America. Among the reasons for the higher costs associated with diabetes is that individuals diagnosed with the disease are also placed at an increased risk for comorbidities such as hypertension, renal failure, retinopathy, neuropathy, and peripheral vascular disease. Improved glucose control, and more highly aligned healthcare, have been shown to decrease an individual's risk for acquiring these comorbidities.[17, 50]

The University of Louisville (Louisville, KY), which self-funds the healthcare benefits for its employees, began to parse their healthcare spending into chronic disease categories in 2009. At that time, an initial analysis suggested that almost $20 \%$ of the total health care expenditures were associated with an enrollee having a diagnosis of diabetes. Faced with this rise in cost and the significant morbidity and mortality that are associated with the disease, the University of Louisville (UofL) human resources leadership decided to seek meaningful solutions centered around diabetes with the stated goals of improving the health of the diabetic enrollees and decreasing the rate of the annual rise in the healthcare costs associated with this population.

While telephonic based programs have traditionally been used in the care of patients and enrollees with chronic conditions such as hypertension, diabetes, hyperlipidemia, and depression, the results have been generally modest.[59] UofL decided, however, to initiate a pharmacist-led program of medication therapy management (MTM) in a high-touch environment, based on the Asheville 
Project.[50] This program, created in 1996 by the City of Asheville, North

Carolina used a pharmacist-led intervention program to help it control the rising healthcare costs it faced as a self-insured employer. This manuscript reports the initial results of a high-touch, pharmacist-led program, diabetes centered disease management program at the University of Louisville.

\section{Methods}

In January 2010, a healthcare claims analysis of the employees enrolled in the University of Louisville's health benefit plan suggested the presence of 424 diabetics. All healthcare claims analyzed and identification of members with diabetes was performed by a separate legal entity using a Business Associate Agreement. Raw claims data were collected through the University of Louisville's benefit consultant, Aon Corporation ${ }^{\mathrm{TM}}$ and data analytics were provided by Verisk Analytics $\AA$. Members were determined to have diabetes if they had two or more outpatient claims with diagnosis of diabetes or one inpatient claim with a diagnosis of diabetes from January 2009 to December 2009. Once the database was created, a Paretto curve was created were enrollees were stratified according to amount (dollars) of claims paid in the plan year. Beginning in March 2010,120 individuals with the highest insurance claims were initially recruited for enrollment; later the Diabetes Disease Management Program (DDMP) became available to all UofL Healthcare members diagnosed with type I or II diabetes. Notification of eligibility and recruitment were done with direct mailings and informative luncheons. 
To participate, the enrollees met one-on-one with the designated pharmacist for an initial visit and signed a "contract" indicating their willingness to meet regularly with a pharmacist and the understanding that they must remain active in the program in order to continue to receive the benefit incentives. As a part of the DDMP, all enrollees were required to meet with a diabetic educator for two hours of diabetic training and to meet with a nutritionist for two hours of diet counseling. The pharmacists who participated in the UofL DDMP received additional training in the care of diabetic patients including the American Association of Diabetes Educators Core Concepts course.

\section{Table 1}

\section{Association of American Diabetes Educators Core Concepts Course Objectives for Providers}

1 Pathophysiology, Epidemiology, and Guidelines for Diabetes Care

- ensures providers have understanding of pathogenesis and clinical manifestations of diabetes

\section{Culturally Competent Supportive Care Across Lifespan}

- compassionate and effective communication with patients

3 Teaching and Learning Skills

- focuses on effective methods of providing information to patients

\section{Self- Management Education}

- how to empower patients to manage their diabetes

\section{Program and Business Management}

- skills to efficiently and effectively provide services to patients 
During the initial visit, the pharmacists recorded medical history, current medications, current primary and specialist physicians, and attempted to discern the current level of medical and pharmaceutical understanding of the enrollee as it pertained to diabetes. Systolic and diastolic blood pressure was measured, height and weight were recorded, and BMI calculated. Laboratory values consisting of a Lipid Panel, Basic Metabolic Panel (serum electrolytes, blood glucose, creatinine), and Urinalysis (micro albuminuria) were obtained as well as a point of care glycosylated hemoglobin $(\mathrm{HbA1c})$. In general, the goal was $\mathrm{HbA1c}$ $\leq 7 \%$.

Diabetics with target glucose control (e.g., $\mathrm{HbA} 1 \mathrm{c} \leq 7 \%$ ) were scheduled for follow-up at three-month intervals. However, diabetics with an $\mathrm{HbA1c}$ of $7-8 \%$ and $>8 \%$ were given suggested lifestyle and medication changes and scheduled for a follow-up visit in two months and one month, respectively. The pharmacist also performed a foot exam at each visit to check for signs of neuropathy or vascular disease and checked the patient's vaccination status. Ophthalmology, endocrinology, vascular surgery, cardiology, podiatry, and dental referrals were provided if needed. After each visit a letter was sent by the pharmacist to the patient's primary physician detailing the encounter and any concerns.

To encourage enrollment and as a major incentive for ongoing participation, enrollees received free diabetes testing supplies (including glucometers and test strips) and co-payments for hypertensive, cholesterol lowering, and diabetic medications were waived at the point of sale. Thus, income should not be a barrier to access for critical medications. 
As of October 2011, 210 enrollees were contracted into the DDMP. Seventy-seven (77) of the 210 enrollees have been enrolled for a minimum of 12 months and constitute the dataset for this report. The patients' charts were reviewed under an IRB approved protocol and clinical data including $\mathrm{HbA} 1 \mathrm{c}$, blood pressure, and BMI were analyzed.

By measuring the $\mathrm{HbA} 1 \mathrm{c}$ every three months and abiding by other evidence-based practice guidelines, providers were also helping to reduce the patient's Care Gap Index (CGI). The CGI is a proprietary measure calculated by Verisk Analytics $®$ that quantifies a patient's deviations from evidence-based treatment guidelines. Ultimately, the CGI gives providers a more comprehensive view of a patient's health status and compliance with recommended treatments. The data were then analyzed by conducting a two-way ANOVA with multivariate analysis using SPSS 20.0.0 statistical software.

\section{Results}

To date, 77 individuals have been enrolled for at least 12 months. Of these, 53 were Caucasian, 22 African-American, and 2 Asian. The mean age was 57 years old. There were 52 females and 25 males. Also, 72 had DM2 and 5 had DM1.

A statistically significant reduction in the $\mathrm{HbA1c}$ was observed among the 77 enrollees in this high-touch diabetes management program. After 12 months of enrollment, the mean $\mathrm{HbA} 1 \mathrm{c}$ was reduced from $7.9 \% \pm 0.2 \%$ to $6.9 \% \pm 0.1 \%$ ( $p<0.001$ ) with a goal $\mathrm{HbA} 1 \mathrm{c}$ being $7.0 \%$. Figure 1 shows the average $\mathrm{HbA} 1 \mathrm{c}$ among the 77 enrollees at $0,3,6,9$, and 12 months of enrolling in the DDMP. 
Figures 2, 3, and 4 show the changes in systolic blood pressure (SBP), diastolic blood pressure (DBP), and BMI, respectively at months 0 and 12 .

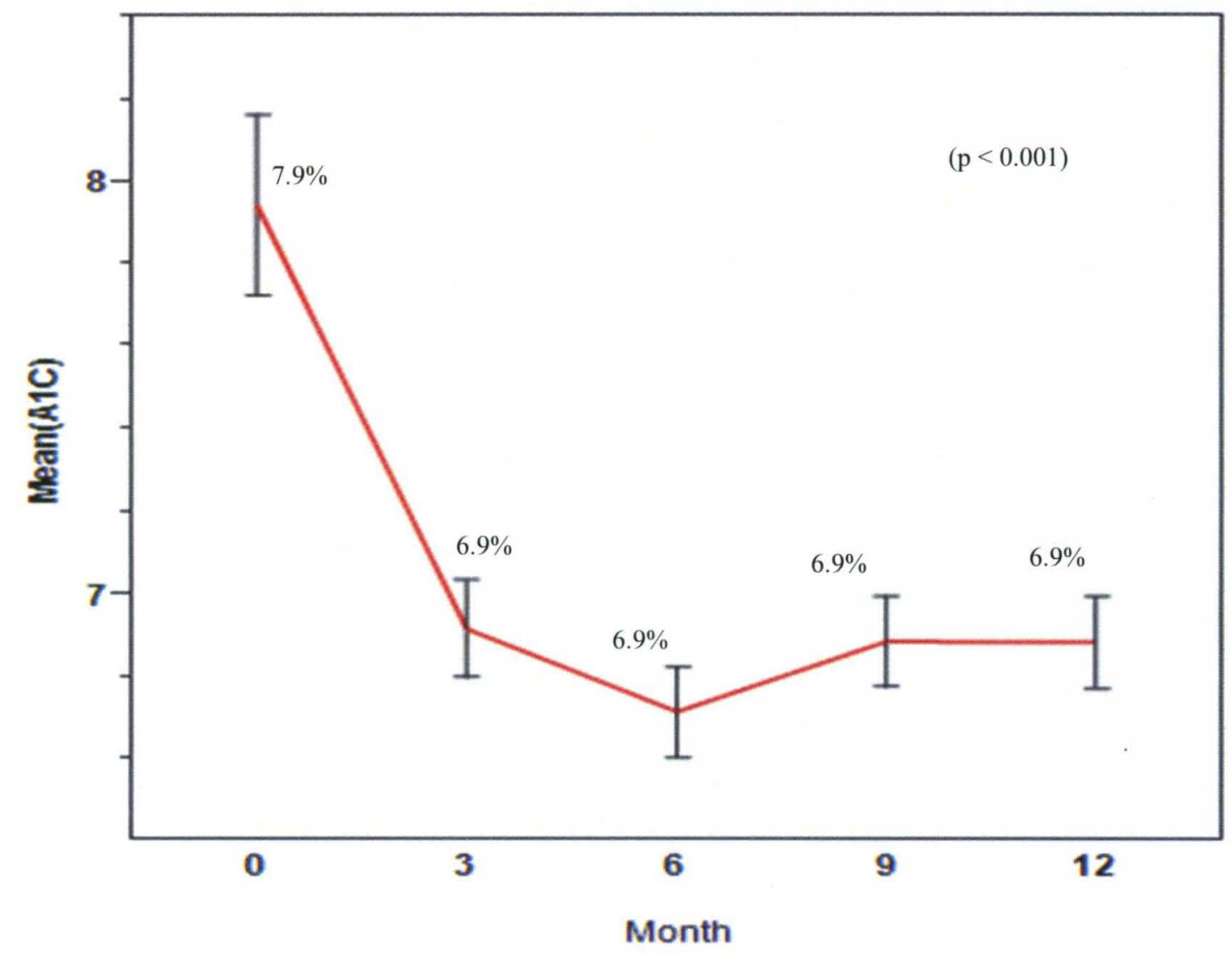

Figure 1. Decrease in the mean $\mathrm{HbA1c}$ at the $0,3,6,9$, and 12 month visits. Overall, the mean $\mathrm{HbA1c}$ experienced a statistically significant decrease from $7.9 \% \pm 0.2 \%$ to $6.9 \% \pm 0.1 \%, p<0.001$. Values depicted are mean \pm standard error. 


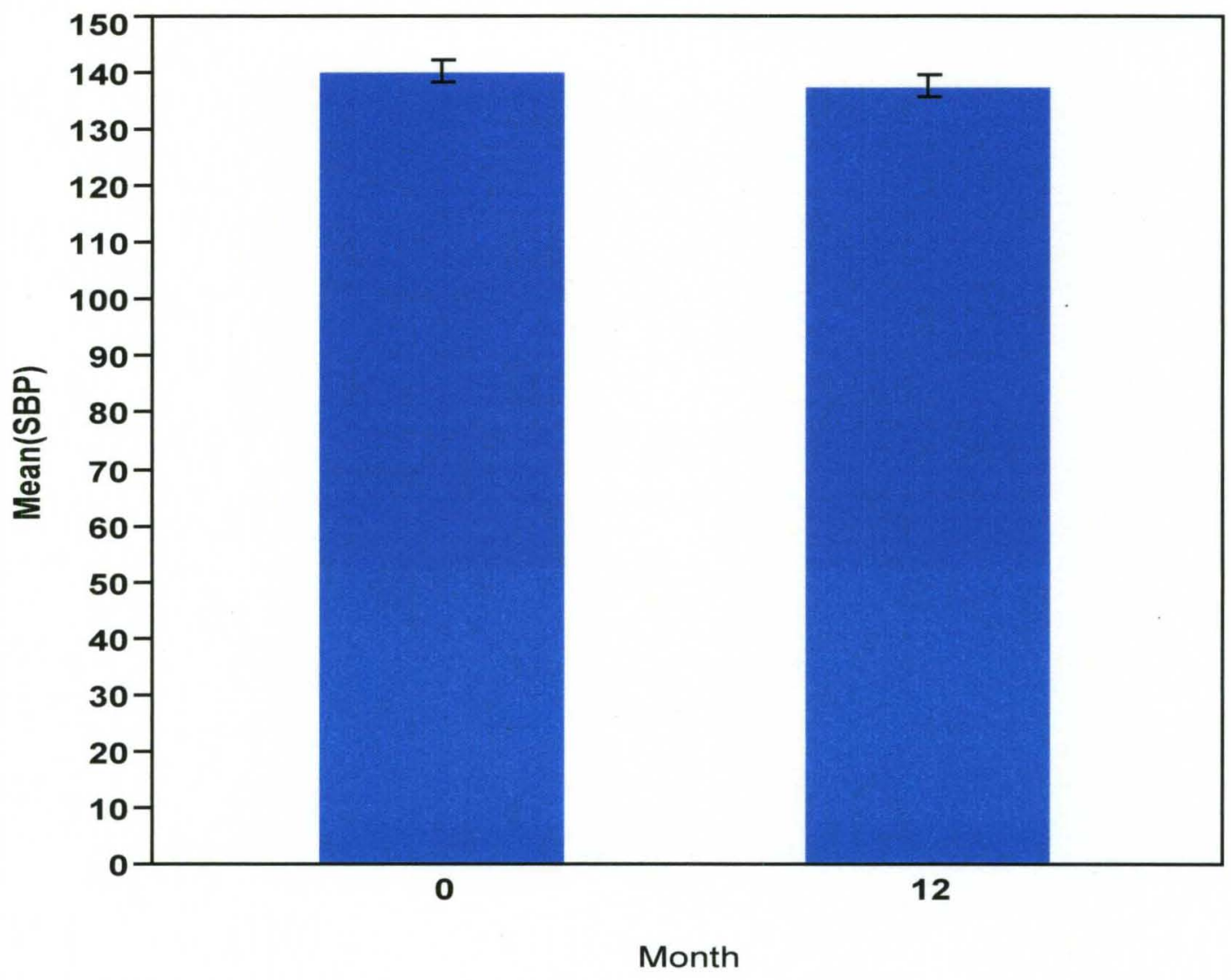

Figure 2. Decrease in the mean systolic blood pressure (SBP) at the 0 and 12 month visits. Overall, the mean SBP experienced a non-statistically significant decrease from $140 \pm 2$ at month 0 to $137 \pm 2$ at month 12 . Values depicted are mean \pm standard error. 


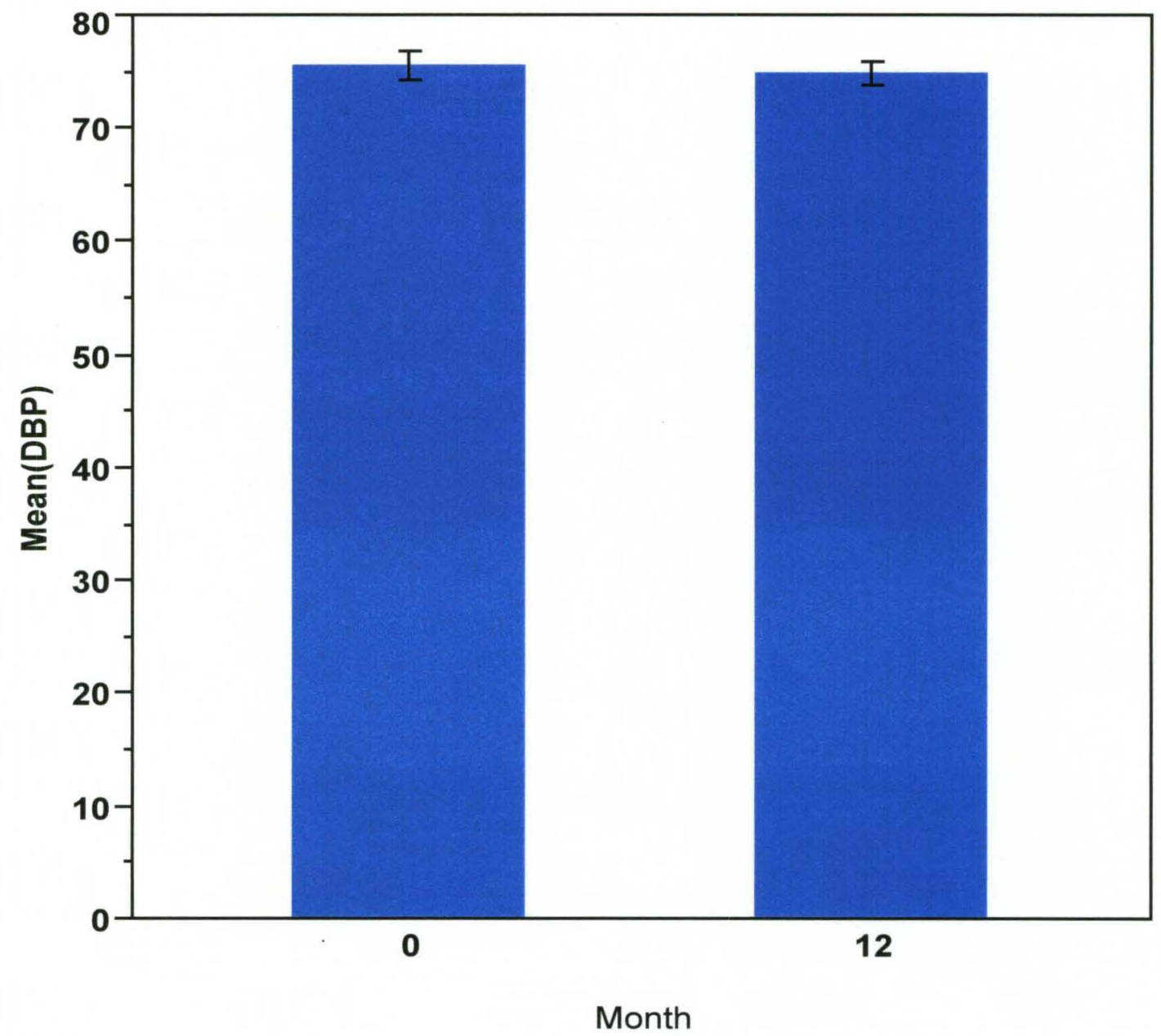

Figure 3. Decrease in the mean diastolic blood pressure (DBP) at the 0 and 12 month visits. Overall, the mean DBP experienced a non-statistically significant decrease from $75 \pm 1$ at month 0 to $74 \pm 2$ at month 12 . Values depicted are mean \pm standard error. 


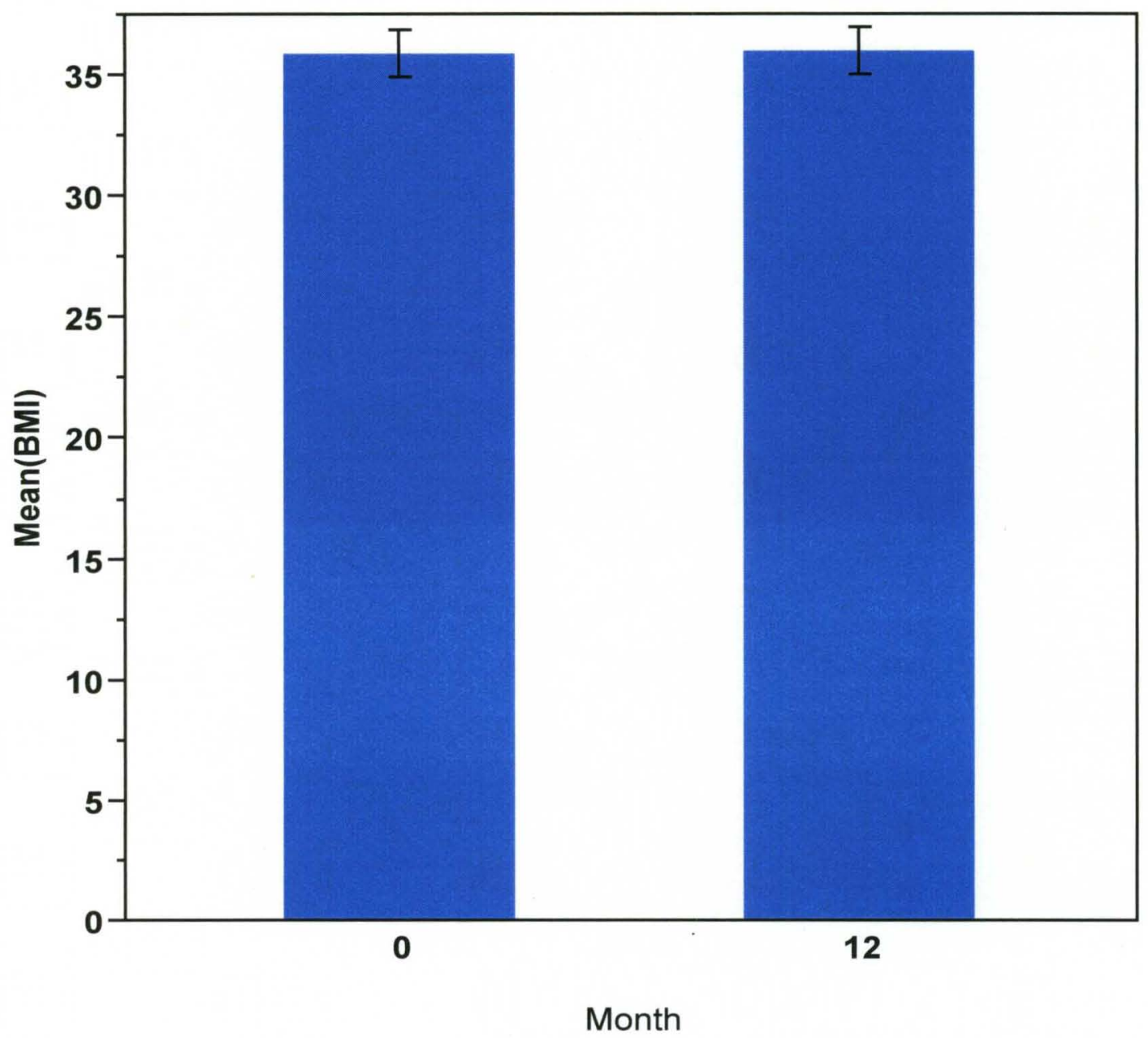

Figure 4. Decrease in the mean basal metabolic index (BMI) at the 0 and 12 month visits. Overall, the mean DBP experienced a non-statistically significant increase from $35.8 \pm .95$ at month 0 to $36 \pm .95$ at month 12 . Values depicted are mean \pm standard error. 


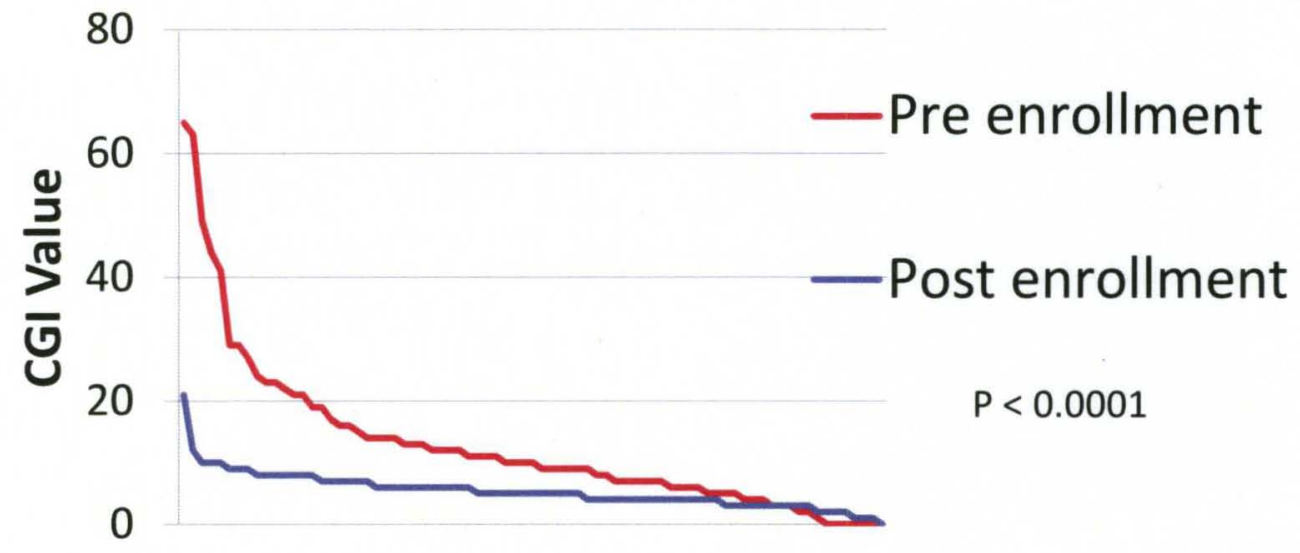

Patient results (highest to lowest value)

Figure 5. Decrease in the mean care gap index (CGI) at the 0 month (preenrollment) and 12 month (post-enrollment) visits. Overall, the mean CGI experienced a statistically significant increase from 14.2 at month 0 (preenrollment) to 5.6 at month 12 (post-enrollment). $\mathbf{N}=\mathbf{7 7}$.

\section{Discussion}

The purpose of this study was to determine if a pharmacist-led DDMP would be successful at improving the health of enrollees diagnosed with diabetes. As such, the primary variables analyzed for this study were HbA1c, SBP, DBP, BMI, and CGI. The primary finding of this study was a significant improvement in blood glucose control and increased compliance; however, there was no significant improvement in SBP, DBP, or BMI.

Currently, American Diabetes Association (ADA) recommendations are that patients maintain their $\mathrm{HbA} 1 \mathrm{c} \leq 7 \%$.[5] Despite the fact that all the enrollees were being seen by a primary care physician, their average $\mathrm{HbA} 1 \mathrm{c}$ upon enrollment was $7.9 \%$. Reasons for elevated $\mathrm{HbA} 1 \mathrm{c}$ levels included medication noncompliance, gaps in knowledge of diet and medication, improper diet, 
infrequent blood glucose testing, and poor physician follow-up. Improvement of the enrollee's $\mathrm{HbA} 1 \mathrm{c}$ was seen within the first three months of enrollment and was maintained throughout the 12-month period. In addition to meeting with the diabetes educator and nutritionist near the time of enrollment, the initial pharmacist visit was also effective at identifying and resolving issues that led to the increased $\mathrm{HbA1c}$ in a timely manner. At each meeting with the pharmacist, individual factors that could have led to an elevated $\mathrm{HbA1c}$ were discussed with the enrollee and individual treatment goals were set. If needed, the pharmacist provided recommendations to the enrollee's primary care physician as to any medication changes that would improve the patient's blood glucose control.

As stated, the CGI is a proprietary measure by Verisk Analytics $\circledast$ that utilizes each enrollee's medical claims data to quantify their deviations from evidence-based diabetes treatment guidelines. For the DDMP, the pharmacist tried to ensure that enrollees were achieving clinical guidelines established by the ADA and other professional organizations. For instance, the pharmacist ensured that patients were receiving annual physical exams, being seen regularly by a podiatrist, remained up to date on all of their vaccinations, and received annual retinal exams. By coordinating among various providers, the pharmacist made sure that enrollees were compliant with all recommended clinical guidelines for the treatment of diabetes. In addition, the pharmacist was also able to review the patient's prescription medication lists and minimize chances of a patient suffering from an adverse drug event (ADE). This attention 
to detail is reflected in the decrease of the average CGI from 14.2 to 5.2 over the 12-month enrollment.

Also, Figure 5 demonstrates that patients with the highest care gaps at enrollment enjoyed some of the largest reductions in CGI thanks to pharmacist adherence to best practice guidelines. Though the way in which the CGI is calculated changes with alterations in recommended guidelines of best practice, it does provide us with an indication of how successful the DDMP has been in increasing the enrollee's treatment compliance.

Collaboration among the various stakeholders involved was essential to ensuring that our DDMP achieved the desired clinical outcome. Specialist physicians at UofL such as nephrologists, podiatrists, and ophthalmologists were recruited to become involved in the DDMP and to provide care for patients with possible diabetic complications. To facilitate participation in the program, administrators met with each specialist physician and asked them to provide clinical criteria that the pharmacist could use in determining whether a referral to their clinic was appropriate. Allowing the various providers an opportunity to have input into the design of the program and to determine how their specialty would be represented helped to ensure that each specialist's clinical boundaries were respected and allowed us to maintain support for the DDMP.

Enrollees were also provided incentives to remain engaged in the DDMP, which created more interest and participation than would have otherwise been expected. Effective provision of disease management services requires longitudinal care and it is essential that enrollees continue to feel the benefits of 
the program so that they remain actively involved. Providing incentives helped ensure that the patients remained in the DDMP even after their $\mathrm{HbA1c}$ was at goal. Follow-up appointments with the pharmacist were scheduled so as to coincide with the date of the patient's next medication refill in order to make ongoing participation as convenient as possible. In addition, we helped to assure continuity of care for the enrollees by only employing a handful of pharmacists to provide clinical services. By maintaining a high retention of enrollees, we helped to ensure that their clinical progress was being maintained and that any deficits in their care were handled in a timely manner.

As third-party payers are increasingly looking for proven methods to reduce healthcare costs, the utilization of pharmacists as mid-level providers of MTM services will increase. There have been numerous pharmacist-led diabetes interventions introduced by third-party payers across the country with similar success in improving the patient's diabetes disease management.[24, 50] In fact, Medicare requires providers of its Part D prescription drug plan to offer MTM services to patients who take five or more medications and whose prescription drug costs exceed a certain threshold.[28, 37, 38] Given the increasing burden that prescription medication costs place on third-party payers, pharmacists' expertise in pharmacotherapy will be increasingly called upon to optimize medication therapy and to minimize errors and duplications in treatment.

The UofL DDMP demonstrated that a high-touch intervention led by pharmacists can be successful at improving clinical outcomes and adherence to treatment guidelines for patients diagnosed with diabetes. This collaborative 
method of healthcare delivery could be duplicated and adapted to provide improved clinical outcomes related to other chronic diseases as well. 


\section{CHAPTER 4}

\section{SUMMARY}

As healthcare costs continue to grow at an unacceptable rate and physicians are increasingly pressured to manage complex patients in a limited amount of time, the need for pharmacist provision of MTM services will grow as well. This thesis demonstrated the utility of a high-touch, pharmacist-led diabetes disease management program in achieving recommended clinical outcomes for patients with diabetes. The significant reduction in $\mathrm{HbA} 1 \mathrm{c}$ was achieved after an average three months of enrollment and sustained throughout the duration of the

DDMP. Moreover, the pharmacist-led DDMP was significant in that it successfully reduced the average CGI of patients enrolled in the DDMP for 12 months. By increasing the patient's adherence to evidence-based guidelines, it is hoped that our patient population would experience decreased complications and associated healthcare expenditures over the long term.

Future studies could focus on expansion of the DDMP to include implementation of a hypertension focused intervention. Additionally, the DDMP could implement interventions focused on other common comorbidities among diabetics such as hyperlipidemia. Successful pharmacist-led hypertension and hyperlipidemia interventions were successfully implemented in the Asheville Project.[60] Given that these conditions are highly prevalent among diabetics, a substantial reduction in morbidity and mortality could be achieved by ensuring 
that patients enrolled in the DDMP are adhering to evidence-based guidelines in these areas. Further, pharmacist interventions could be designed for other chronic conditions with high rates of polypharmacy such as congestive heart failure and COPD.

As the demand for healthcare continues to rise, the pharmacist provision of MTM services will continue to grow in popularity as third-party payers seek to ensure the efficient and effective use of costly medications. Patients will also benefit tremendously from the reduced morbidity and mortality that result from stricter adherence to evidence-based clinical guidelines for diseases such as diabetes. Pharmacist provision of MTM services will be essential to providing comprehensive healthcare as the number of patients requiring complex medication therapy continues to grow.

Future studies could focus on expansion of the DDMP to include implementation of a hypertension or BMI focused intervention, similar to the Asheville Project. 


\section{REFERENCES}

1. Roger P. Austin MS, R., CDE, Polypharmacy as a Risk Factor in the Treatment of Type 2 Diabetes. Diabetes Spectrum, 2006. 19(1): p. 13-16.

2. Alice K. Pau, P. Polypharmacy Problems: Drug Interactions In the Multidrug Therapy of HIV Infection. The PRN Notebook, 2002.

3. Kathleen Woodruff M.S., C. Preventing Polypharmacy in Older Adults. American Nurse Today, 2010. 5.

4. Bussel, B.v., et al., Polymorbidity in diabetes in older people: consequences for care and vocational training. Postgraduate Medical Journal, 2007. 83(986): p. 763-767.

5. Association, A.D., Standards of Medical Care in Diabetes - 2011. Diabetes Care, 2011. 34: p. S11 - S61.

6. Cynthia J. Wiley, P., et al., Polypharmacy with Oral Antidiabetic Agents: An Indicator of Poor Glycemic Control. The American Journal of Managed Care, 2006. 12(8): p. 435-440.

7. Emslie-Smith, A., J. Dowall, and A. Morris, The Problem of Polypharmacy in type 2 diabetes. British Journal of Diabetes and Vascular Disease, 2003. 3: p. 54-56.

8. Emily Hajjar PharmD, B., CGP, P. ANgela C. Cafiero, CGP, and P. Joseph T. Hanlon, MS, BCPS, Polypharmacy in Elderly Patients. The American Journal of Geriatric Pharmacotherapy, 2007. 5(4): p. 350-351.

9. Gu Q., C. Dillon, and V. Burt, Prescription Drug Use Continues to Increase: U.S. Prescription Drug Data for 2007-2008. NCHS Data Brief, D.o.H.a.H. Services, Editor 2010, National Center for Health Statistics: Hyattsville, MD.

10. Pirmohamed, M., et al., Adverse drug reactions as cause of admission to hospital: prospective analysis of 18820 patients. British Medical Journal, 2004. 4(15). 
11. Bates, D.W., Drugs and Adverse Drug Reactions. Journal of the American Medical Association, 1998. 279(15): p. 1216-1217.

12. Curt Mueller, P.D., P.D. Claudia Schur, and P.D. Joan O'Connell, MHS, Prescription Drug Spending: The Impact of Age and Chronic Disease Status. American Journal of Public Health, 1997. 87(10): p. 1626-1629.

13. Foundation, H.J.K.F. Prescription Drug Trends. 2010 May 2010 11/18/2011]; Available from: http://www.kff.org/rxdrugs/upload/3057-08.pdf.

14. Foundation, H.J.K.F. Prescription Drug Costs: Background Briefs. Prescription Drug Costs 2010 February 2010 11/18/2011]; Available from: http://www.kaiseredu.org/lssue-Modules/Prescription-DrugCosts/Background-Brief.aspx.

15. Strausberg, J. and J. Hasford, Drug-related admissions and hospitalacquired adverse drug events in Germany: a longitudinal analysis from 2003 to 2007 of ICD-10-coded routine data. BMC Health Services Research, 2011. 11.

16. Chan, M., F. Nicklason, and J.H. Vial, Adverse drug events as a cause of hospital admission in the elderly. Internal Medicine Journal, 2001. 31: $p$. 199-205.

17. Prevention., C.f.D.C.a., National Diabetes Fact Sheet: National Estimates and General Information on Diabetes and Prediabetes in the United States, 2011, C.f.D.C.a.P. Department of Health and Human Services, Editor 2011: Atlanta, Georgia.

18. Tai-Seale, M., T.G. McGuire, and W. Zhang, Physician and Patient Behavior: Time Allocation in Primary Care Office Visits. Health Services Research, 2007. 42(5): p. 1871-1894.

19. Richard Baron, M.D., What's Keeping Us So Busy in Primary Care? A Snapshot from One Practice. New England Journal of Medicine 2010. 362(17): p. 1632-1636.

20. Devine, E.B., et al., Strategies to optimize medication use in the physician group practice: The role of the clinical pharmacist. The Journal of the American Pharmacists Association, 2009. 49(2): p. 181-191. 
21. Lucian L. Leape, M., et al., Pharmacist Participation on Physician Rounds and Adverse Drug Events in the Intensive Care Unit. Journal of the American Medical Association, 1999. 281(3): p. 267-270.

22. Schellevis, F.G., et al., Consultation Rates and Incidence of intercurrent morbidity among patients with chronic disease in general practice. The British Journal of General Practice 1994. 44(383): p. 259-262.

23. Solutions., P.f. Chronic Conditions: Making the Case for Ongoing Care. 2004 11/18/2010]; Available from: http://www.partnershipforsolutions.org/DMS/files/chronicbook2004.pdf.

24. Fera, T., et al., The Diabetes Ten City Challenge: Interim clinical and humanistic outcomes of a multisite community pharmacy diabetes care program. Journal of the American Pharmacists Association, 2008. 48(2): p. 181-190.

25. Cranor, C.W., The Asheville Project: short-term outcomes of a community pharmacy diabetes care program. Journal of the American Pharmaceutical Association, 2003. 43(2): p. 149-159.

26. Brian J. Isetts PhD, B., Evaluating Effectiveness of the Minnesota Medication Therapy Management Care Program. Final Report, in Evaluating Effectiveness of the Minnesota Medication Therapy Management Care Program2007, Minnesota Department of Human Services.

27. Elizabeth Chrischilles, P., et al., lowa Medicaid Pharmaceutical Case Management Program: Final Report-Executive Summary, in lowa Medicaid Pharmaceutical Case Management Program 2002.

28. Joan Davanzo, P.D., M.S.W., et al., Medication Therapy Management Services: A Critical Review: Final Report, 2005, The Lewin Group.

29. Nedzad Pokskic, M.S., et al., Ontario family physician readiness to collaborate with community pharmacists on drug therapy management Research in Social and Administrative Pharmacy, 2011. 7: p. 39-50.

30. Ross, L.A., Pharmacists as mid-level practitioners/providers. The Annals of Pharmacotherapy 2011. 45(6): p. 810-820.

31. Sardinha, C., Indian Health Service: Paving the Way for Pharmaceutical Care. Journal of Managed Care Pharmacy, 1997. 3(1): p. 41-43. 
32. Louis Flowers, P., MS, et al., U.S. Public Health Service Commissioned Corps Pharmacists: Making a Difference in Advancing the Nation's Health. Journal of the American Pharmacist Association, 2003. 49(3): p. 446-452.

33. Richard N. Herrier, P., R.W. Boyce, and P. David A. Apgar, Pharmacistmanaged patient-care services and prescriptive authority in the U.S. Public Health Service. Hospital Formulary 1990. 25(1): p. 67-80.

34. Richard M. Church, P., The Expanded Role of Pharmacists in the Public Health Service: An overview of a pharmacy practice model. Hospital Formulary, 1989. 24(9): p. 526-527,530,532.

35. Clause, S., et al., Prescribing Privileges Among Pharmacists in Veteran's Affairs Medical Centers. American Journal of Health-System Pharmacists, 2001. 58: p. 1143-1145.

36. Ogden, J.E., A. Muniz, and A.A. Patterson, Pharmaceutical Services in the Department of Veterans Affairs. American Journal of Health-System Pharmacists, 1997. 54: p. 761-765.

37. Jacqueline Kostick, P. Medicare MTM Services: A New Frontier. Medscape Pharmacists, 2006. 7.

38. Cynthia Tudor, P.D., Medicare Prescription Drug Benefit Manual: Chapter 7 - Medication Therapy Management and Quality Improvement Program, C.f.M.M.S. Department of Health and Human Services, Editor 2006, Centers for Medicare \& Medicaid Services: Washington, D.C. p. 1-26.

39. Pharmacists, A.S.o.H.-S. State Medicaid Programs Utilizing the Services of Pharmacists. 2009 11/02/2011]; Available from: http://www.ashp.org/DocLibrary/Advocacy/GAD/Getlnvolved/MedicaidProgr ams.aspx.

40. Glenn M. Hackbarth, J.D. and P.D. Robert D. Reischauer, Report To The Congress: Medicare Coverage of Nonphysician Practitioners, C.f.M.M.S. Department of Health and Human Services, Editor 2002, Medicare Payment Advisory Commission: Washington, D.C.

41. Glenn M. Hackbarth, J.D. and P.D. Robert D. Reischauer, Report to the Congress: Medicare Payment to Advanced Practice Nurses and Physician Assistants, D.o.H.a.H. Services, Editor 2002 Medicare Payment Advisory Commission Washington, D.C. 
42. Pharmacy, A.A.o.C.o. Resources. Pharmacy for You 2009 [cited 2011 10/18/2011]; Available from: http://www.aacp.org/resources/student/pharmacyforyou/Documents/Pharm D.pdf.

43. ACCP, The Definition of Clinical Pharmacy. American College of Clinical Pharmacy, 2008. 28(6): p. 816-817.

44. Takahiro Higashi, M.D., et al., The Quality of Pharmacologic Care for Vulnerable Older Patients. Annals of Internal Medicine, 2004. 140(9): p. 714-720.

45. Mark Monane, M.D. and M.P.H. Lisa A. Cataldi, Safe Prescribing: Interdisciplinary Solutions. Geriatric Times, 2000. 1(1).

46. John A. Gans, P., et al., Perspectives of MTM Service Implementation, in American Pharmacists Association Medication Therapy Management Digest2008, American Pharmacists Association: Washington, D.C.

47. Melissa M. Blair, et al., Pharmacist privileging in a health system: Report of the Qualified Provider Model Ad Hoc Committee. American Journal of Health-System Pharmacists, 2007. 64: p. 2373-2381.

48. Galt, K.A., Credentialing and privileging for pharmacists. American Journal of Health-System Pharmacists, 2004. 61: p. 661-670.

49. Claxton, K.L. and P. Wojtal, Design and Implementation of a credentialing and privileging model for ambulatory care patients. American Journal of Health-System Pharmacists, 2006. 63: p. 1627-1632.

50. Cranor, C.W., The Asheville Project: short-term outcomes of a community pharmacy diabetes care program. Journal of the American Pharmaceutical Association, 2003. 43(2): p. 149-159.

51. Centers for Medicare \& Medicaid Services, The Affordable Care Act: Helping Providers Help Patients, A Menu of Options for Improving Care, C.f.M.M.S. Department of Health and Human Services, Editor 2011: Washington, D.C.

52. Berwick, D.M., Medicare Program; Medicare Shared Savings Program: Accountable Care Organizations. Final Rule, C.f.M.M.S. Department of Health and Human Services, Editor 2011, Centers for Medicare \& Medicaid Services, Washington, D.C. 
53. Thomas F. Tonniges M.D., F. and C.S. M.D., History of the Medical Home Concept. Pediatrics, 2004. 113: p. 1473-1478

54. Grace M. Kuo, et al., Collaborative drug therapy management services and reimbursement in a family medicine clinic. American Journal of HealthSystem Pharmacists, 2004. 16(4): p. 343-354.

55. Orszag, P., Growth in Health Care Costs, in Committee on the Budget, C.B. Office, Editor 2008, Congressional Budget Office: Washington, D.C. p. 14.

56. Meyerson, N., et al., The Long-Term Outlook for Health Care Spending, C.o.t.U. States, Editor 2007, Congressional Budget Office: Washington, D.C.

57. Fabbio, B. Reversing the Healthcare Cost Curve. Chiefexecutive.net, 2011.

58. Promotion, N.C.f.C.D.P.a.H., Diabetes At-A-Glance, C.f.D.C.a. Prevention, Editor 2011, Department of Health and Human Services: Atlanta, Georgia.

59. R. Currell, et al., Telemedicine versus face to face patient: effects on professional practice and health care outcomes (Review). Cochrane Database of Systematic Reviews, 2000(2)

60. Barry A. Bunting, Benjamin H. Smith, and S.E. Sutherland, The Asheville Project: Clinical and economic outcomes of a community-based long-term medication therapy management program for hypertension and dyslipidemia. Journal of the AMerican Pharmacists Association, 2008. 48(1): p. 23-31. 


\section{CURRICULUM VITAE}

NAME: BENJAMIN MAURICE RISNER

ADDRESS: 103 SOUTH BECKLEY STATION ROAD

LOUISVILLE, KY 40245

DOB: May 4, 1983

\section{EDUCATION AND TRAINING:}

The University of Louisville School of Medicine $L$ Louisville, $K Y$ Doctor of Medicine, May 2009

The University of Louisville $L$ Louisville, KY

Bachelor of Science, May 2005

Area of focus: Chemistry w/Business concentration

PROFESSIONAL SOCIETIES:

American Medical Association - 2005 - present

Kentucky Medical Association - 2005 - present

Phi Delta Epsilon - 2005 - 2009

Christian Medical Dental Association 2005 - 2009

\section{PUBLICATIONS:}

Risner, Benjamin BS; Nyland, John EdD, PT, SCS, ATC, FACSM; et al. "Orthopedic In-Training Examination Performance: A Nine-Year Review of a Residency Program Database." Southern Medical Journal; August 2008, Volume 101, Issue 8, pp. 791-796

\section{PRESENTATIONS:}

1. Risner, Benjamin BS; Nyland, John EdD, PT, SCS, ATC, FACSM; et al. Orthopaedic In-Training Examination Performance: A Nine-Year Review of a Residency Program Database. Poster Presentation Idea Festival Louisville Fall 2006 
2. Risner, Benjamin BS; Nyland, John EdD, PT, SCS, ATC, FACSM; et al. Orthopaedic In-Training Examination Performance: A Nine-Year Review of a Residency Program Database. Oral Presentation SGEA Annual Conference 2007

3. Risner, Benjamin, M.D.; Cissel, Alice, M.H.A.; Claypool, Tina, PharmD; Matthews, Donna, RN, BSN, CCM; Morgan, Jesse, PharmD; Goldstein, Richard M.D., Ph.D.

UofL Diabetes Disease Management Program: Utilizing PharmD's To Improve Diabetes Care. Poster Presentation University of Louisville Graduate Research Symposium Spring 2011

4. Risner, Benjamin, M.D.; Cissel, Alice, M.H.A.; Claypool, Tina, PharmD; Matthews, Donna, RN, BSN, CCM; Morgan, Jesse, PharmD; Goldstein, Richard M.D., Ph.D.

Clinical Results of a Pharmacist-Led High-Touch Diabetes Management Program Poster Presentation Research Louisville Fall 2011 